\title{
CHILDREN AND COMPETENCE TO CONSENT: GILLICK GUIDING MEDICAL TREATMENT IN NEW ZEALAND
}

\author{
Kathryn McLean ${ }^{*}$
}

The House of Lords' decision of Gillick was delivered in 1985. The Court held that children who are under 16 years, but have the intelligence and understanding to be competent to give consent to a particular treatment, may give consent for themselves. To date New Zealand's Parliament and courts have not adopted Gillick. The competence principle from Gillick has nonetheless gained a degree of acceptance in New Zealand medical and legal circles. This paper discusses the status of Gillick in New Zealand. It also analyses the majority judgments in Gillick to ascertain the exact principle that should be extracted from the decision.

The main focus of this paper is to consider the application of the Gillick competence principle in the New Zealand context. In researching this paper, the author undertook four interviews with various New Zealand doctors to ascertain their practices and views of Gillick. This paper examines the questions of: who should assess Gillick competence; when it is appropriate to invoke the Gillick principle; and the issues involved in how a doctor could assess Gillick competence. Practical guidance is offered through a proposed set of guidelines for assessing Gillick competence which are appended to this paper.

\footnotetext{
"A child becomes an adult when he realises that he has a right not only to be right but also to be wrong."

Thomas Szasa

Hungarian-born psychiatrist

The Second Sin (1973) "Childhood"
}

\footnotetext{
* This paper was submitted in fulfilment of the LLB (Hons) requirements at Victoria University in 1999.
} 


\section{INTRODUCTION}

Growing up is difficult. It encompasses the middle ground between childhood and adulthood. Maturity is spasmodic: different people develop at different rates. The challenge for law is to deal with and accommodate this unique stage in development. This paper is concerned with the law's ability to accommodate children in the area of medical treatment.

The 1985 decision of the House of Lords in Gillick $v$ West Norfolk and Wisbech Area Health Authority and another ${ }^{1}$ held that children who are under 16 years, but have the intelligence and understanding to be competent to give consent to a particular treatment, may give consent for themselves. The parental right to consent terminates when a child is deemed Gillick-competent. The assessment of Gillick competence is a question of fact for the doctor to determine in each case.

In reality, most medical decisions concerning children are dealt with by doctors, parents and children. Gillick competence is not often an issue. When competence assessments are made, they are rarely controversial. Nevertheless, the principle of Gillick competence may serve as a useful facet of our medical and legal systems. It is the object of this paper to discuss the status and application of Gillick in the New Zealand context.

Part II of this paper will consider the status of Gillick in New Zealand. The extent of its present acceptance will be discussed. This paper will tender the view that Gillick should be expressly adopted into New Zealand law.

Part III will determine the nature of the principle in Gillick. This will require an analysis of the majority judgments given by the House of Lords in Gillick. Later English case law that has built upon Gillick and created a distinction between giving and refusing consent will then be briefly reviewed and criticised. Examination will show that the nature of the Gillick principle that should be considered for the New Zealand context provides that children with sufficient understanding and maturity may give or refuse consent to medical treatment.

Part IV will discuss the practical application of the Gillick principle. It will first consider who should assess children for Gillick competency. Secondly, it will examine when it is appropriate to invoke the Gillick principle. Thirdly, the issues involved in how a doctor could assess Gillick competence will be discussed. A proposed set of guidelines for assessing Gillick competence is appended to this paper.

1 Gillick $v$ West Norfolk and Wisbech Area Health Authority and another [1986] 1 AC 112 (HL) [Gillick]. 
II THE STATUS OF GILLICK IN NEW ZEALAND

\section{A Legislation}

The primary statutory rule applying to minors and medical consent is set out in section 25(1) of the Guardianship Act 1968. Section 25(1) states:

The consent of a child of or over the age of 16 years to any donation of blood by him, or to any medical, surgical, or dental procedure (including a blood transfusion) to be carried out on him for his benefit by a person professionally qualified to carry it out, shall have the same effect as if he were of full age.

A child of or over 16 years may therefore give effective consent for medical treatment. Section 25(1) does not explicitly give competent children under 16 years the right to give effective consent. However, neither does it necessarily exclude the possibility. It could be interpreted as merely laying down an age at which all persons will definitely be able to give consent while still allowing the possibility that those persons under this age who are competent can give consent.

\section{B Case Law}

The status of Gillick in New Zealand is uncertain. Although Gillick is part of the English common law, it does not automatically constitute part of the laws of New Zealand. ${ }^{2}$ At present, no New Zealand court has yet expressly adopted the Gillick case. Conversely, no court has rejected the Gillick approach for New Zealand.

\section{Other Sources}

Despite the lack of explicit statutory or case law adopting the principle from Gillick in regards to medical treatment, alternative sources indicate considerable approval for the

2 Although decisions of the House of Lords have considerable persuasive precedent value, they are not binding on the New Zealand courts. 
adoption of Gillick. These sources include academic writing, ${ }^{3}$ the Office of the Health and Disability Commissioner ${ }^{4}$ and Medical Council publications. ${ }^{5}$

\section{Code of Health and Disability Services Consumers' Rights (1996)}

The Code steers well clear of using age-related thresholds and focuses on the competence of an individual consumer. Rights 7(2) and (3) illustrate this approach:

(2) Every consumer must be presumed competent to make an informed choice and give informed consent, unless there are reasonable grounds for believing that the consumer is not competent.

(3) Where a consumer has diminished competence, that consumer retains the right to make informed choices and give informed consent, to the extent appropriate to his or her level of competence.

This appears to reflect an express adoption of the principle in Gillick. ${ }^{6}$

\section{Psychology studies}

Psychology studies have generally indicated that children younger than 16 years are often capable of the processes and abilities involved in responsible decision-making. ${ }^{7}$

Furthermore, studies have also indicated that it is desirable to give children the opportunity to consent when appropriate. A study by Lewis et al indicates that children are capable of learning how to take responsibility for themselves in their health care

3 See: WR Atkin "Parents and Children: Mrs Gillick in the House of Lords" [1986] NZLJ 90. DB Collins Medical Law in New Zealand (Brooker \& Friend, Wellington, 1992). Graeme Austin "Righting a Child's Right to Refuse Medical Treatment: Section 11 of the New Zealand Bill of Rights Act and the Gillick-competent child" (1992) 7 Otago LR 578; Morag McDowell "Medical Treatment and Children: Assessing the Scope of a Child's Capacity to Consent or Refuse Consent in New Zealand" (1997) 5 J Law \& Med 81.

4 Annie Fraser "The Informed Consent Process and the Application of the Code to Children" in Ministry of Health Consent in Child and Youth Health: Information for Practitioners (Ministry of Health, Wellington, 1998) 51, 53.

5 David Cole Medical Practice and Professional Conduct in New Zealand (The Medical Protection Society, New Zealand, 1988) 24. David Cole Medical Practice in New Zealand: A Guide to Doctors Entering Practice (Medical Council of New Zealand, Wellington, 1995) [A Guide to Doctors].

6 Rights 7(2) and 7(3) will also apply to the likes of the elderly and handicapped.

7 See: J Piaget and B Inhelder The Psychology of the Child (Basic Books, New York, 1969). Priscilla Anderson "Consent to Children's Surgery and Intensive Medical Treatment" (1990) 17 J of Law \& Soc 52. L A Weithorn and S B Campbell "The Competency of Children and Adolescents to Make Informed Treatment Decisions" (1982) 53 Child Development 1589. 
decisions. ${ }^{8}$ Therefore, allowing children an active role in the decision-making process will help teach children to look after themselves and to take responsibility for their own health care. This would allow for an incremental learning process, rather than instantaneously bestowing responsibility on achieving a set legal age. Additionally, studies show that where children are given an active role in decision-making, the treatment is more likely to be effective. ${ }^{9}$

\section{Present New Zealand situation}

I interviewed four doctors in researching this paper. ${ }^{10}$ These interviews indicated that the principle from Gillick is already being used in practice in New Zealand. The two general practitioners (GPs) that I interviewed were unsure of an exact legal age where consent became valid. Both considered that capacity to consent was not determined by a particular age limit, but was more dependent on the individual patient's abilities. One GP commented that "It [capacity to consent] seems to have moved down to 12 [years of age] or even less in some circumstances". ${ }^{11}$ The hospital paediatrician identified the age of 16 as determinative to legal consent and also acknowledged Gillick as having some impact. The paediatrician also commented that Gillick was more likely to be utilised in general practice and family planning. ${ }^{12}$ The doctor who specialises in sexual health issues was familiar with Gillick and its application. ${ }^{13}$ Therefore, despite the lack of explicit approval for Gillick in statute or case law, there is already acceptance, and indeed use, of a capacity-based approach to consent.

\section{Conclusion}

Doctors are already utilising a capacity-based approach to consent. This is a situation where it is desirable for the law to catch up with practice. Doctors are at the 'coal-face' in

8 CE Lewis, MA Lewis, A Lorimer and B Palmer "Child Initiates Care: The Use of School Nursing Services by Children in an 'Adult-Free' System" (1977) 60 Pediatrics 499. A good and brief discussion of Lewis et al's findings can be found in: John Devereaux "The Capacity of a Child in Australia to Consent to Medical Treatment - Gillick Revisited?" (1991) 2 Oxford J of Legal Studies $283,301$.

9 Richard E Redding "Children's Competence to Provide Informed Consent for Mental Health Treatment" [1993] Washington and Lee Law Review 695, 708-709.

10 Interview with anonymous general practitioner on 4 August 1999. Interview with anonymous general practitioner on 10 August 1999. Interview with anonymous hospital paediatrician on 13 August 1999. Interview with anonymous doctor who specialises in sexual health issues on 18 August 1999

11 Interview with anonymous general practitioner on 4 August 1999.

12 Interview with anonymous hospital paediatrician on 13 August 1999.

13 Interview with anonymous doctor who specialises in sexual health issues on 18 August 1999. 
medical dealings with children. The fact that doctors have clearly gauged that there are situations where it is appropriate and desirable for children under 16 to be able to give or refuse consent for themselves should inform our legal development.

However, none of this detracts from the fact that Gillick has not yet received express approval in New Zealand statutes or case law. A clear statement of the legal position in New Zealand by Parliament or the courts would provide clarity for doctors and patients and would remove any uncertainties regarding the parties' legal positions and potential liability.

\section{THE GILLICK PRINCIPLE}

\section{A Analysis of Gillick}

The main question in the English case of Gillick was whether a doctor could lawfully provide contraceptive advice and prescriptions for a girl under 16 years of age. The majority of the House of Lords held that, in certain circumstances, it would indeed be legal. The two leading majority judgments were delivered by Lords Scarman and Fraser.

Lord Scarman's judgment allows children under 16 to give effective consent in two types of situations. First, children with sufficient maturity and understanding so as to be capable of giving consent will not require their parents' consent because the children themselves have been judged to be responsible enough to make authoritative decisions about their own body and health. The second type of situation is when exceptional circumstances arise in which a doctor considers it is in the best interests of the child to proceed without parental consent. Lord Scarman explains: ${ }^{14}$

He [a doctor] may prescribe only if she [a patient] has the capacity to consent or if exceptional circumstances exist which justify him in exercising his clinical judgment without parental consent.

The adjective 'clinical' emphasises that it must be a medical judgment based on what he honestly believes to be necessary for the physical, mental and emotional health of his patient.

Lord Scarman provides a non-exhaustive list of examples where a doctor would be justified to act in the child's best interests and proceed without the parents' consent: emergency, parental neglect, abandonment of the child, and inability to find the parent. ${ }^{15}$

It is the first type of situation that is the well-recognised principle from Gillick. This general principle is encapsulated in Lord Scarman's comment that: ${ }^{16}$ 
a minor's capacity to make his or her own decision depends on the minor having sufficient understanding and intelligence to make the decision and is not to be determined by reference to any judicially fixed age limit.

This is a clear rejection of the status-based approach where settled age limits determine rights. Furthermore, both Lords Scarman and Fraser recognised that the parents' right and duty to decide for their child, which exists for the benefit and well-being of the child, terminates when the child achieves sufficient maturity and understanding. ${ }^{17}$

Lord Scarman's test requiring "sufficient understanding and intelligence" is a test to measure a child's competence to exercise his or her autonomy in medical decision-making. Gillick-competent children are entitled to give consent because they have sufficient maturity, understanding and intelligence to make decisions about their own body and life. Such decisions should be respected.

It should be noted that, in accordance with the idea articulated in Gillick that children mature and develop gradually, children do not suddenly achieve full competence at a certain time. Competence to consent will come incrementally with growing maturity and experience. A child may be competent to make autonomous decisions in some areas but not others. Accordingly, a doctor will assess a child for competence in regard to a particular treatment. Competence depends on the particular abilities of the individual child. Gillick requires that these abilities should be recognised and, when such abilities enable a child under 16 to be capable of exercising their autonomy, that they should be respected.

In comparison, Lord Fraser's overwhelming motivation for allowing minors to give effective consent to contraceptive advice and treatment was to protect the health and wellbeing of the child. He acknowledged that sometimes it is best for the child's well-being not to require parental involvement in treatment decisions: ${ }^{18}$

It is notorious that children of both sexes are often reluctant to confide in their parents about sexual matters, and ... to abandon the principle of confidentiality for contraceptive advice to girls under 16 might cause some of them not to seek professional advice at all, with the consequence of exposing them to 'the immediate risks of pregnancy and of sexuallytransmitted diseases'.

Lord Fraser produced a list of factors that a doctor must consider and be satisfied of before proceeding without the child's parents' consent. The final factor required "that her [the patient's] best interests require him [the doctor] to give her contraceptive advice,

17 Gillick above n 1, 170-171 per Lord Fraser, and 184, 186 per Lord Scarman.

18 Gillick above n 1, 173 per Lord Fraser. 
treatment or both without the parental consent". ${ }^{19}$ This requirement is obviously tailored to the particular facts in Gillick and pertains to a situation where contraceptive advice and prescriptions may be given.

Lord Fraser's requirements provide for a situation of 'last resort': every effort is to be made to encourage parental involvement and only in exceptional circumstances, where the health of the child is threatened, is it desirable to proceed with only the child's consent. According to Lord Fraser, the real motivation behind allowing under-16 year-olds to receive treatment without parental involvement is that the treatment "is best for the welfare of the particular child". 20

This 'best interests' requirement is inconsistent with the purpose of the competence test in Gillick which requires a child to have "sufficient understanding and intelligence". A competence test which is reliant on measuring maturity, understanding, and intelligence is really about determining a person to have the capacity to exercise autonomy over their own body. The point about an autonomous decision is that it is the individual's choice; the decision is valid however unreasonable or undesirable it may appear to others. Autonomy requires that all competent people have responsibility and authority over their own bodies. It should not be dependent on or curtailed by a doctor's opinion of the individual's best interests. This approach is confirmed by the House of Lords in Airedale NHS Trust $v$ Bland: 21

it is established that the principle of self-determination requires that respect must be given to the wishes of the patient, so that if an adult patient of sound mind refuses, however unreasonably to consent to treatment or care by which his life would or might be prolonged, the doctors responsible for his care must give effect to his wishes, even though they do not consider it to be in his best interests to do so.

Furthermore, the English Court of Appeal's decision in St George's Healthcare NHS Trust $v S$ affirms such an approach. ${ }^{22}$

Lord Fraser's own acceptance of a test measuring "sufficient understanding and intelligence" 23 conflicts with his apparent best-interests motivation. Lord Fraser's reasoning potentially produces a very undesirable result: children who are competent to

19 Gillick above n 1, 174 per Lord Fraser.

20 Gillick above n 1, 173 per Lord Fraser.

21 Airedale NHS Trust v Bland [1993] AC 789, 864 (HL) per Lord Goff.

22 St George's Healthcare NHS Trust v S [1998] 3 WLR 936, 950 (CA) per Judge LJ.

23 Gillick above n 1, 171 per Lord Fraser. 
consent will be given treatment only if their decision accords with the doctors' own opinions of their best interests. ${ }^{24}$ Such an approach undermines the principle of autonomy which requires respect for a competent individual's decision.

Therefore, the clear approach of Lord Scarman is preferable as it best provides for children under 16 years old. The autonomous decisions of mature children can be respected as they should, and children under 16 who receive treatment because it is in their best interests to do so will not have to disguise such treatment behind a test of competence. $^{25}$ Lord Scarman's approach endorses the integrity of both principles of autonomy and best interests.

If Gillick is adopted into New Zealand law, it is desirable that it is Lord Scarman's twolimb approach that is identified as the preferred principle from the case. However, this paper is primarily concerned with examining the first limb of Lord Scarman's approach which concerns children who have sufficient maturity to be competent to give consent.

\section{B Consent and Refusal of Consent}

\section{The English cases on refusal of consent}

The English Court of Appeal has built upon the Gillick decision and modified its application in cases of refusal of consent. The cases of $\operatorname{Re} R^{26}$ and $\operatorname{Re} W^{27}$ have limited a Gillick-competent child's ability to refuse consent to medical treatment: a competent child's refusal of consent may be overridden by his or her parents' consent or by a court's consent. $^{28}$

24 This would not produce a situation where a doctor would be forced to treat a patient against the doctor's judgment. A doctor should not be able to overrule a Gillick - competent child's consent and deem them incompetent because the doctor believes that such treatment is not in the patient's best interests. However, a doctor may decline to administer treatment if he or she considers that it would be damaging to the patient. It is more appropriate, honest and ethical for a doctor in such a situation to refuse to administer treatment on the grounds that it would be unconscionable for him or her to proceed.

25 Criticism of the "mature minor" doctrine in America has noted this problem of disguising 'best interests' motivations for allowing treatment behind the apparently capacity based mature minor doctrine. See: Michelle Oberman "Minor Rights and Wrongs" (1996) 24 The Journal of Law, Medicine \& Ethics 127.

26 Re R (A Minor) (Wardship: Consent to Treatment) [1991] 3 WLR 592 (CA) [Re R].

27 ReW(A Minor) (Medical Treatment: Court's Jurisdiction) [1992] 3 WLR 758 (CA) [Re W].

28 In Re R the child's refusal of consent was overridden using wardship. In $R e W$ the child's refusal of consent was overridden through the parens patriae jurisdiction. No particular significance was attached to either of these modes; they were simply the instruments that the applications were made under in each case. 


\section{Why the Gillick principle should include refusal of consent}

Although the particular facts of the Gillick decision concerned children under 16 being able to give effective consent, the Gillick principle should be interpreted as encompassing refusal of consent also. Gillick recognised that children's abilities develop gradually over time and at different rates. The ability to take responsibility for one's own medical decisions is not limited to situations of giving consent. The principle of autonomy encompasses not only the right to say yes, but also the right to say no. Logically, the Gillick competence principle should apply whether a child is giving consent or refusing consent as long as he or she has been determined Gillick-competent to make that particular decision. It is no more difficult for a doctor to assess whether a child has capacity to give consent than to assess whether the child has the capacity to refuse consent.

Furthermore, Gillick has also recognised that when children are competent to exercise their autonomy and take responsibility for their own medical decisions, their parents' power to consent is terminated: ${ }^{29}$

the parental right to determine whether or not their minor child below the age of 16 will have medical treatment terminates if and when the child achieves a sufficient understanding and intelligence to enable him or her to understand fully what is proposed.

This conflicts with Lord Donaldson's approach in $\operatorname{Re} R$ and $\operatorname{Re} W$ where he recognised concurrent rights to consent for children and their parents. However, once a child has been held to be responsible to make an autonomous decision regarding his or her own body, regardless of whether it involves giving or refusing consent, that decision should not be open to veto by parents or any other party. The child has been judged to be mature enough to take responsibility for him or herself and it is therefore his or her decision alone.

This approach accords with that taken in the Australian High Court case of Department of Health $\mathcal{E}$ Community Services (NT) $v$ JWB and SMB (Re Marion). ${ }^{30}$ McHugh J relied on Gillick when he commented that: ${ }^{31}$

the parent's authority is at an end when the child gains sufficient intellectual and emotional maturity to make an informed decision on the matter in question.

In Re Marion, the Australian High Court elected not to take the opportunity to adopt the approach of $\operatorname{Re} R .^{32}$

Gillick above n 1, 188-189 per Lord Scarman.

30 Department of Health \& Community Services (NT) v JWB and SMB (Re Marion) (1992) 66 ALJR 300 (HCA) [Re Marion].

31 Re Marion above n 30, 340 per McHugh J. 
The New Zealand Bill of Rights Act 1990 and the Code of Health and Disability Consumers' Rights provide further reasons why New Zealand should follow the Australian line in Re Marion rather than the English approach in Re R and Re W. Section 11 of the Bill of Rights Act states that "Everyone has the right to refuse to undergo any medical treatment". "Everyone" includes competent minors. Similarly, Right 7(7) of the Code expressly allows all consumers the right to refuse medical treatment. ${ }^{33}$ This is an express recognition of the importance of not forcing competent persons to undergo treatment against their wishes. A child who is competent to make decisions and consent to medical treatment should not be forced to endure unwanted treatment. ${ }^{34}$ Accordingly, the Gillick competence principle that New Zealand should consider adopting involves the right to refuse consent as well as the right to give consent. ${ }^{35}$

\section{PROPOSAL FOR FURTHERING GILLICK IN NEW ZEALAND}

\section{A Who Should Assess Gillick Competence}

The House of Lords in Gillick considered that doctors were the appropriate persons to assess Gillick competence. One of the concerns with having doctors make such an assessment is that they will be swayed by their professional biases. Doctors are particularly influenced by their view of a patient's best interests. As already discussed, this raises the concern that doctors will lean towards finding patients Gillick-competent

32 It should be noted that Re Marion concerned a 14 year old girl who was intellectually impaired and suffered from severe deafness, epilepsy and behavioural problems. However, this does not detract from the fact that the Court's obiter comments show an acceptance of the Gillick principle that parents' rights terminate when the child becomes competent and therefore support the finding that parents do not continue to hold concurrent rights.

33 For more discussion of this point see McDowell, above n 3.

34 The hospital paediatrician whom I interviewed discussed a hypothetical situation where a 15 year old who had undergone long periods of intensive treatment for leukemia should have their wishes respected if they decided to discontinue treatment, even if their family wanted to continue with treatment. The paediatrician commented "that situation, you would respect that, and if the parents wanted to push on with treatment you would refuse to do it. It's more about you being in touch with what their wishes are. If you feel that it's appropriate, then you go along with it, if you feel it's really inappropriate you wouldn't go along with it. And that sort of situation it would be very appropriate. Another situation where a 15 year old comes in with a new diagnosis of leukemia which is easily treatable and says 'I don't want to have any treatment', you wouldn't goalong with that ... you would spend a lot of time with them and try and convince them therapy was very worthwhile".

35 If Gillick competence is taken to include the right to refuse consent, parents of unwilling children would not be able to invoke section 25(3) of the Guardianship Act 1968 to force treatment provided that the child was considered Gillick-competent. 
when they agree to the doctor's proposed treatment, but will judge them incompetent if they disagree with the proposed treatment.

Furthermore, there is the concern that within the medical community there will be inconsistency in the application of Gillick due to personal views and beliefs. This may be particularly noticeable in areas that raise social, religious or moral issues such as contraception, vaccinations and blood transfusions.

However, some degree of subjectivity is inherent in such a decision; anyone, doctor or not, who makes such an assessment will be partially influenced by their own views and beliefs. Additionally, as prejudices go, the influence of best interests of the patient is not such a bad bias with which to be afflicted. Concerns with subjectivity should not prevent doctors from assessing Gillick competence.

One doctor I interviewed considered that Gillick competence decisions were "nothing new" to doctors and that "doctors make difficult moral decisions just about every day ... and they're probably pretty good at doing it". ${ }^{36}$ Another doctor pertinently queried: "Well, who else is going to do it? They [doctors] may not be appropriate, but who is more appropriate?". 37 The confidentiality and trust characteristics of the doctor-patient relationship prevent wider discussion of the patient's competence. Ultimately the responsibility for a competence assessment must be the doctor's: it is the doctor who will be administering treatment or refraining from giving treatment and therefore it must be the doctor who is satisfied that he or she is justified in doing so.

It remains to consider what standard doctors should be judged by when assessing Gillick competence. ${ }^{38}$ An assessment of Gillick competence involves judgment and discretion; there is no actual right or wrong answer to be discovered. Accordingly, an objective standard requiring that the doctor make their decision as the 'reasonable doctor' would make it too high a standard. However, a wholly subjective standard would make the decision unquestionable and untouchable. Perhaps a more appropriate standard to apply is one similar to judicial review standards: that a fair procedure must be followed and that the decision arrived at must not be so wholly unreasonable that no reasonable doctor could have made it. It should be noted that there is not one way of ensuring fair procedure; fair procedure may be achieved in numerous ways and processes. Such a standard could recognise the discretionary nature of such a decision while not rendering it entirely untouchable from criticism.

\footnotetext{
36 Interview with anonymous general practitioner on 4 August 1999.

37 Interview with anonymous general practitioner on 10 August 1999.

38 A standard to judge doctors by may be necessary in disciplinary hearings or court actions.
} 


\section{B When to Invoke the Gillick Competence Test}

\section{Breadth of consent}

All interactions between doctors and patients require consent. If consent is not given, then the doctor may be liable for battery if any touching occurs. Additionally, doctors may be liable in negligence or for breach of a fiduciary relationship if they fail to obtain effective consent before treatment.

The process of consent does not necessarily require elaborate procedures and written forms. In situations where a patient is merely consulting a doctor, implied consent is sufficient. A tacit agreement is formed between the parties by the patient's action of seeking consultation and the patient's acquiescence during examination. Therefore, a doctor has the authority to take a history of the patient's health, to ask family and lifestyle based questions and to undertake a routine medical clinical examination. ${ }^{39}$

If more "intimate and intrusive" 40 examination is required, it is necessary for the doctor to explain the procedure, ask for consent, and obtain the express consent of the patient. Verbal consent may be sufficient for more minor procedures. However, procedures which are potentially harmful will usually have the express consent of the patient being evidenced in a written consent form signed by the patient. ${ }^{41}$

Therefore, the principle of the Gillick-competent child may potentially be invoked in all interactions between doctors and patients.

\section{Effect of presumption of competence}

The Code of Health and Disability Services Consumers' Rights creates a presumption of competence for all consumers. Right 7(2) states:

Every consumer must be presumed competent to make an informed choice and give informed

consent, unless there are reasonable grounds for believing the consumer is not competent.

The definition of "consumer" in the Code "includes a person entitled to give consent on behalf of that consumer." However, this does not actually exclude the child who is receiving treatment from the status of "consumer". Accordingly, all children are entitled to the rights given to all consumers under the Code.

This interpretation of children being "consumers" is strengthened by the notion that all children, regardless of their capacity to consent, must be entitled to receive the basic health

\footnotetext{
39 A Guide to Doctors above n 5, 15.

40 A Guide to Doctors above n 5, 15.

41 A Guide to Doctors above n 5, 15
} 
care rights embodied in the Code. Services at an appropriate standard, effective communication and information, the right to complain, treatment with respect and dignity are essential for all patients. Therefore, the presumption of competence in Right $7(2)$ applies to all people, including those under 16 years of age. ${ }^{42}$

Right 7(2) may create a legal presumption, yet it does not really accord with reality. Realistically, children are viewed as incompetent to give informed consent. In practice, no health practitioner actually presumes a 5 year old competent till proven otherwise. Reality and practicality work from a presumption of incompetence for children. This is consistent with Gillick also. Under Gillick, parents' consent is necessary in most situations where children receive medical treatment. The House of Lords viewed cases where children were competent to give consent as exceptional types of situations. Gillick really requires a presumption of incompetence which will be overturned when a child is proven to possess the necessary maturity and capacity to give or refuse consent.

Similar to the United Kingdom approach in Gillick and the Australian approach in Re Marion, the laws in the United States also work from a presumption of incompetence. ${ }^{43}$ New Zealand is unusual in adopting a presumption of competence.

The potential effects of a presumption of competence for child patients have not really been thoroughly examined. It is unclear what kind of an obligation on health practitioners is created by the existence of a presumption of competence.

Potentially, a legal presumption of competence could require health practitioners to undertake an examination of all children under 16 years of age in every treatment situation to determine the capacity of the child to give or refuse consent. An investigation would have to be undertaken with every occurrence of consent to overturn or affirm the presumption for competence. If the presumption is not overturned, the child continues to be considered competent and any purported consent of the parents could be invalid. This could be potentially problematic in a situation where a young child is being treated and the parents' ability to consent is simply assumed to be effective. Therefore, doctors would be required to undertake an inquiry of some nature.

Considerations of reality and practicality require that doctors should not be bound to undertake a specific and conscious inquiry in every treatment situation for an under 16 year old. Notwithstanding the existence of a presumption of competence, doctors must be allowed a discretion to determine when it is appropriate to undertake an express inquiry

42 The Office of the Health and Disability Commissioner has expressed the view that "all the rights in the Code are applicable to consumers of health and disability services, regardless of the age of the consumer, including the right to give informed consent." Fraser, above n 4, 53.

43 Redding, above n 9, 743. 
into the competence of a child patient and when "reasonable grounds" exist so that no express inquiry is necessary.

The presumption of competence can probably be overturned in a significant number of cases where children under 16 receive medical treatment without specific and express inquiry. Extreme youth should provide "reasonable grounds" to overturn the presumption. Gillick will be most relevant when dealing with 12 to 15 year olds, yet it may still be appropriate to consider it for younger children for more minor procedures. However, no hard and fast rule can be made concerning a minimum age where Gillick competency does not have to be considered. Such a rule would go against the spirit and principle of Gillick.

A clear guide as to the exact nature of such an inquiry is necessary to help aid the medical profession in carrying out their legal duties and avoiding the liability that doctors could potentially incur.

\section{Exercising a doctor's discretion}

Before a consumer makes a choice or gives consent, Right 6(2) of the Code requires a doctor to provide the information that a reasonable consumer needs, in that consumer's circumstances, to make an informed choice or to give informed consent. Right 6(2) holds doctors to the standard of a reasonable patient's expectations. Therefore, it needs to be considered when a reasonable patient would expect to be informed about the Gillick principle. This is a rather amorphous standard for doctors to adhere to: doctors may want to cover themselves from liability by at least bringing up the possibility of Gillick in borderline situations.

It certainly seems reasonable that patients should and would expect to know that they potentially have the right to give effective consent for themselves. Right 6(2) should require a doctor to give the information to a patient, where Gillick competence may potentially be a relevant consideration, so that he or she may be entitled to give consent by him or herself.

There are three basic scenarios where Gillick is likely to be invoked. The first likely scenario is when a child under 16 comes to consult a doctor on his or her own. Obviously, obtaining the parents' consent is not an immediate option. Therefore considering the Gillick competence of the child may provide the doctor with an effective consent to allow treatment.

The second scenario is when a doctor is dealing with a child accompanied by their parents, yet the child and parents have different views and wishes on the treatment. It is obvious where the child is vocal about their contrary opinion that the Gillick competence of the child should be examined. It may be appropriate that this occurs in consultation with 
both the child and the parents. Yet it will not always be clear under this scenario that Gillick should be invoked: a child may be silent on their wishes and simply acquiesce to their parents' views because they do not realise that they potentially have a right to decide for themselves. Doctors should always seek to ascertain the patient's own views and potentially mention Gillick to ensure that the child is not conforming to his or her parents' views either unwillingly or ignorantly.

The third potential scenario occurs when a child is accompanied by their parents and both child and parents voluntarily and knowingly agree on treatment. Although it may seem that the parents' consent is sufficient ground on which to proceed, a doctor should nonetheless encourage the child to learn to exercise their autonomy and give them the opportunity to be responsible for their own body and decisions. Gillick should be invoked where the child appears to exhibit a level of maturity that warrants inquiry.

A restriction on this is that no child should ever be forced to exercise Gillick competence. Even if found competent, a child should be able to give their parents, either impliedly or explicitly, the ability to consent or to refuse consent for possible treatment. Doctors certainly should not be open to liability if a child is deemed competent yet still wants their parents to give effective consent and sign the relevant forms.

\section{How to Implement the Gillick Competence Test}

\section{Requirements for informed consent}

Informed consent is not an isolated event: it is a process of informing the patient, encouraging discussion, and allowing patients appropriate time in which to consider the options and come to their own decisions. The requirements of informed consent are that it must be voluntary, informed, and competently given. ${ }^{44}$

The patient must be informed that he or she has a choice. Under Right 5 of the Code all consumers have a right to be informed at a level and in a language appropriate to their understanding. When dealing with younger patients, doctors may have to be especially aware of explaining complex terminology and keeping information clear and simple but not to the extent of "dumbing down" the information.

To ensure effective consent, doctors must provide information and explanation to patients about their state of health, the medical options available to them and any details of

44 Ron Paterson "Legal and Ethical Dilemmas" in Ministry of Health Consent in Child and Youth Health: Information for Practitioners (Ministry of Health, Wellington, 1998) 42, 42. 
the procedures involved. This will involve outlining the possible risks and benefits, side effects and failure rates of any proposed treatments. ${ }^{45}$

These general principles of informed consent are applicable and necessary where children under 16 years give or refuse consent.

\section{Assessing Gillick competence}

From their first interaction with a patient, doctors will have begun to assess a patient's competence and abilities; the process of assessment will be an on-going one. The appropriate time to conclude an assessment of a Gillick competence is once a child has evinced a choice in regard to a particular treatment decision. Until this point it is unclear whether the assessment concerns the child giving or refusing consent. Furthermore, to judge competence a doctor may require a child to articulate the reasons for his or her decision. This cannot be done until the child has made his or her decision. Nevertheless, there is no formula that must be applied to conduct an assessment; it is dependent on the individual practitioner's style.

An assessment of Gillick competence concerns a particular treatment situation. A doctor must determine if this particular individual is competent to give or to refuse consent in regards to a specific treatment. Therefore, a child may be competent to consent to some treatments, but not to others. ${ }^{46}$ A child may also be considered competent to give

45 Ministry of Health Consent in Child and Youth Health: Information for Practitioners (Ministry of Health, Wellington, 1998) 3.

46 Some examples given by one of the general practitioners I interviewed were that it would be appropriate for a nine year old to come in and be treated for a sore throat, an ingrown toenail or an ear infection. However, it would be unlikely that a nine year old would be competent to consent to removal of tonsils. As an example of where a child's refusal of consent would be valid is where a parent brings a child in to have a mole check. A mole does not appear dangerous, but the parent wants it removed. If the child refused to have the mole removed in such a situation, the doctor commented that "you can't force a child to undergo treatment, you can't physically do it, maybe if they were 10 or 12 , you'd have to restrain them."

Interview with anonymous general practitioner on 10 August 1999.

An example of where a minor may be likely to be incompetent to consent is for a heart transplant operation, as occurred in the very recent English case of $R v M$ where Johnson J commented that the "view was that $\mathrm{M}$ is an intelligent fifteen year old girl whose wishes should carry considerable weight. Nevertheless their view was that $\mathrm{M}$ felt overwhelmed by her circumstances and the decision she was being asked to make. A few weeks before $\mathrm{M}$ had been a healthy active girl, who loved netball and swimming, but now she is very ill and close to death. Events have overtaken her so swiftly that she has not been able to come to terms with her situation". $R v M$ (15 July 1999) unreported, High Court (Family Division), Newcastle (Engl.) at <http:/ / tap.ccta.gov.uk.courtser/ judgments.nsf/38ccf0153146a9 f88025656d005df623>, para12. 
consent to treatment, but not competent to refuse consent to that same treatment. ${ }^{47}$ Such decisions may require different degrees of understanding and maturity.

The hospital paediatrician whom I interviewed considered that the use of Gillick in hospitals was much more limited than in general practice. Treatment in hospital usually concerns more serious injury or illness. Accordingly, many children under 16 will not have the understanding or maturity to deal with these significant treatment decisions alone. ${ }^{48}$ Furthermore, family is almost always involved when treatment is so serious that it necessitates hospital care. Indeed, in such situations it is generally highly desirable to have family involvement. ${ }^{49}$

\section{Factors to consider when dealing with children}

No exhaustive guidelines on the factors to be considered when dealing with children have been attempted for the New Zealand context. The 1998 Conference on Consent in Child and Youth Health provided basic guidance for health practitioners. A practitioner should consider the following questions when assessing capacity: ${ }^{50}$

- Does the patient understand why they need the intervention?

- Does the patient understand what the intervention involves and what it is for?

47 For instance, one of the general practitioners I interviewed gave the example of a nine year old who had tonsillitis and would be capable of consenting to taking penicillin to treat the condition. However, the same child might not be able to understand the full implications of what rheumatic fever might do to her were she to refuse treatment. In such a situation it was more appropriate that her parents should accept the responsibility of refusing consent.

Interview with anonymous general practitioner on 10 August 1999.

48 The hospital paediatrician commented: "I think informed consent for children who are less than 16 is a very difficult thing to achieve and obviously the younger they are the more difficult that is ... I don't believe that they should have any significant say in that ... I don't thing they are really capable of looking at the big picture."

Interview with anonymous hospital paediatrician on 13 August 1999.

49 The hospital paediatrician whom I interviewed commented: "When children feel threatened, that their life is threatened, they will usually seek protection in the thing they know best, and that is their family. So it is unlikely that a family and a child in that situation are going to be in significant conflict." The paediatrician further noted the importance and benefit for the family to be involved in treatment decisions: "Something like a diagnosis of cancer has an impact on a whole family ... it has significant ramifications for the rest of the family and the parents and I do believe that you can't extinguish their rights to have input into those major life-threatening decisions."

Interview with anonymous hospital paediatrician on 13 August 1999.

50 Ministry of Health, above n 45, 15. 
- Does the patient understand the probable benefits and risks and what the alternatives are?

While these are certainly pertinent factors to consider, they are not exhaustive. Gillick itself provides some guidance as to the level of competence required. Lord Scarman implies that more than just mere cognitive understanding is necessary; Gillick-competent children must be able to address the wider implications of their decisions: ${ }^{51}$

It is not enough that she [the patient] should understand the nature of the advice which is being given: she must also have a sufficient maturity to understand what is involved. There are moral and family questions, especially her relationship with her parents.

Although Lord Scarman's comments are based primarily on a factual situation where contraceptive advice is being given, they can nonetheless serve as a guide for other kinds of medical treatment.

A further case considering the application of Gillick competence is the recent English case of Re L (Medical Treatment: Gillick Competency). ${ }^{52}$ A 14 year old girl required blood transfusions during surgery to treat her serious burn injuries. She refused to consent to the blood transfusions because of her Jehovah's Witness faith. Her family supported her decision. Sir Stephen Brown held that she was not Gillick-competent as the doctors had chosen not to fully inform her, as they felt it was inappropriate, about the "horrible" deterioration and death she would suffer if she refused treatment. ${ }^{53}$ It is very difficult to judge this situation having only the bare facts. However, it may be verging on the unacceptably paternalistic to refuse to fully inform a 14 year old, who is described as mature for her age, about her life threatening condition. The second reason the Court gave for judging the girl incompetent was the "sheltered life" she had led. Her Jehovah's Witness faith "has been formed by her in the context of her own family experience and the Jehovah's Witness' meetings where they all support this view." ${ }^{54}$ It was also described as a "religious belief which does not in fact lend itself in her mind to discussion." 55 This type of view was to be distinguished from "the constructive formulation of an opinion which occurs with adult experience." 56

51 Gillick above n 1, 189 per Lord Scarman.

52 Re L (Medical Treatment: Gillick Competency) [1999] 2 FCR 524 (Family Division).

$53 \operatorname{Re} L$ above n 52, 526-527 per Sir Stephen Brown.

54 Re L above n 52, 527 per Sir Stephen Brown.

$55 \operatorname{Re} L$ above n 52, 527 per Sir Stephen Brown.

56 Re $L$ above $\mathrm{n} 52,527$ per Sir Stephen Brown. 
In addition to the considerations noted in case law, Richard Redding has provided a useful summary of the typical standards used to determine competence. The common models are: 57

- factual understanding of the problem and the treatment alternatives;

- rational decision-making processes;

- appreciation for the personal implications of the decision;

- ability to make and communicate a choice;

- a reasonable choice;

- general competence.

The first model is obviously a relevant and necessary requirement for a Gillickcompetent child to exhibit. This level of understanding is necessary for any person giving informed consent. Lord Scarman's comments in Gillick indicate that Redding's third model is also applicable when determining competence for children: that Gillick-competent children must have an appreciation for the wider implications of their decision. They may need to display an understanding of the effects of their decision on their relationships with families and friends.

The second and fourth models mentioned by Redding are useful in that they can serve as evidence that a child possesses the necessary maturity and ability to be judged Gillickcompetent. The fact that a child has used rational decision-making processes and possesses the ability to make and communicate a choice can demonstrate that the child possesses a good understanding of the situation and that he or she is mature and capable enough to make medical care decisions. Rational decision-making focuses on the process of decision-making rather than the result. A child who can identify relevant factors and consider them to arrive at a decision has demonstrated rational decision-making.

The general competence test that is Redding's sixth model involves a consideration of overall competence, "which may be determined with reference to diagnosis, appearance, or prior behaviour." 58 These are relevant for a doctor to consider when judging Gillick competence. It is this sort of interaction that will assist a practitioner in assessing the maturity and intelligence of a child. ${ }^{59}$ Doctors who have had previous dealings with a

57 Redding, above n 9, 710.

58 Redding, above n 9, 710 .

59 Results of interviews overwhelmingly showed that doctors rely heavily on general interaction with a patient to help determine his or her competency.

Interview with anonymous general practitioner on 4 August 1999. 
child should allow that experience to better inform themselves on the child's abilities and family background. A family doctor may have a distinct advantage when assessing a child and judging when to involve family members in decision-making. ${ }^{60}$

Redding's fifth model requiring a reasonable decision is not an appropriate consideration for a health practitioner to take into account. An autonomous decision is valid regardless of its apparent "reasonableness". Although it is an inevitable human flaw that doctors determining a child's competence are going to be influenced to some degree by their personal views on the decision, they must nonetheless strive for objectivity and limit the inquiry to the patient's competence rather than their view of the "correctness" of the patient's decision.

\section{$V$ CONCLUSION}

Current practice in New Zealand indicates that the competence principle in Gillick is already well established and accepted by the health system. However, express adoption by Parliament or the courts has not yet occurred. This is a situation where the law needs to "catch up" with practice. In all likelihood, the New Zealand courts will adopt Gillick when the opportunity arises. Parliament could remedy the situation more efficiently with an amendment to the Guardianship Act 1968.

It is highly desirable that the competence principle in Gillick should form part of the laws governing informed consent to medical treatment. Although assessments of Gillick competence will inevitably be influenced by doctors' personal views and their overall concern for patients' best interests, competence based assessments are still preferable rather than an age based status approach.

Overwhelmingly, our system of law is characterised by its creation of objective standards and principles which can be applied to groups of people. It is a challenge to our legal system to recognise and accommodate a particular individual's situation. ${ }^{61}$ However, the provision of medical treatment is an area where it is possible and practical to deal with an individual's situation. Doctors see each patient on an individual basis and tailor the situation to that patient. Determining rights by way of age limits is not

Interview with anonymous general practitioner on 10 August 1999.

Interview with anonymous doctor who specialises in sexual health issues on 18 August 1999.

60 One general practitioner I interviewed commented that it is a distinct advantage to understand the family background and that it is "much more difficult if you don't know the family".

61 Examples of other areas where law is evolving to accommodate an individual's characteristics include recognising battered women's syndrome and relaxing limitations restrictions for abuse victims. 
appropriate in the area of health care which is overwhelmingly personal. It is desirable that the law recognise this. Gillick is concerned with the difficult phase of young people "growing up" and it endeavours to recognise and accommodate an individual's situation in regard to medical treatment. As Lord Scarman pertinently noted in Gillick: "[this] case is the beginning, not the conclusion, of a legal development". ${ }^{62}$

62 Gillick above n 1, 414 per Lord Scarman. 


\section{APPENDIX}

\section{PROPOSED GUIDELINES FOR ASSESSING GILLICK COMPETENCE}

When to Invoke Gillick Competence

Consent will be an issue in all interactions between practitioners and patients. Gillick becomes relevant when the patient is under 16 years of age. It is most likely to be useful when dealing with older children.

The issue of Gillick competence should be raised when a reasonable patient would expect to be informed of it. A child who has the maturity and ability to give or refuse consent would probably expect to be told about Gillick competence. Therefore, practitioners should invoke Gillick competence where a patient appears to exhibit a level of maturity that warrants inquiry. Practitioners do not have to have drawn a conclusion about a patient's competence before raising the issue of Gillick competence with them. This is a vague guide, yet it is desirable that practitioners have a discretion about when it is appropriate to invoke Gillick competence.

There are three scenarios where Gillick is likely to be useful:

\section{Where a child seeks treatment without his or her parents}

This situation obviously raises the need for an inquiry into the child's competence to give or refuse consent.

Where a child seeks treatment accompanied by his or her parents, but they have different views on the treatment

A Gillick competence inquiry is probably relevant where children are vocal about their objections. Children may also be quiet about their wishes as they are intimidated by their parents' presence or unaware that could give or refuse consent themselves. It may be appropriate to ask parents to leave and to speak to a child alone. Alternatively, Gillick competence may be discussed with children and parents together.

Where a child seeks treatment accompanied by his or her parents and they all agree on treatment

It is desirable to aid children in learning to exercise their autonomy and to take responsibility for their health decisions. Therefore, it may be appropriate to undertake an inquiry of Gillick competence to encourage mature children to make their own decisions. In such situations, practitioners will effectively obtain consent from both children and their parents.

Children should not be forced to exercise Gillick competence if they do not want to. A child may give their parents, either impliedly or explicitly, the ability to give or refuse 
consent for treatment. This is unlikely to be that common as most children who want their parents to make their decisions are probably not Gillick-competent.

\section{How to Implement the Gillick Competence Test}

Assessing Gillick competence is an ongoing process rather than a one-off event. It can begin with a practitioner's first interaction with a patient and probably cannot be concluded until the patient has evinced a decision which has been discussed. There is no fixed way of assessing Gillick competence. It will be determined by a health practitioner's own experience and style.

An assessment requires a unique inquiry tailored to an individual patient concerning a particular treatment situation. Practitioners must satisfy themselves that a patient is competent to give consent or is competent to refuse consent to a particular treatment.

To assist a practitioner in measuring the competence of an under 16 year old, two general areas should be considered:

- the patient's factual understanding of the problem and treatment, and

- the patient's appreciation for the personal implications of the decision.

In assessing competence for a particular treatment, practitioners may rely on any general interaction that they have with a patient, such as a patient's presentation and conversation. To help judge the abilities and maturity of a patient, practitioners should consider whether the patient has demonstrated rational decision-making processes: identifying relevant factors, considering them, expressing a decision and giving their reasons for it. Practitioners should utilise any impressions and knowledge from previous experience with the patient, the family, and religious and cultural background of the patient and their family. A practitioner may find it useful to consult with other staff involved (provided that this does not breach doctor-patient confidentiality).

\section{The Patient's Factual Understanding of the Problem and Treatment}

The Code of Health and Disability Consumers' Rights requires that practitioners explain to patients:

- $\quad$ the patient's medical condition

- $\quad$ all available medical treatment options

- $\quad$ the purpose and aims of any proposed treatment

- $\quad$ any procedure that may be involved under the proposed treatment and

- the probable risks, benefits, side effects, and failure rates of any proposed treatment. 
The Code further requires that a practitioner, when giving such explanation, must use language and terms that the patient understands.

Practitioners should assess a patient's understanding. This may involve:

- Practitioners asking patients if they understand; whether they want anything repeated; and whether they have any questions.

- Patients being told how important it is for them to have a proper understanding of their condition and the potential treatment. It should be made plain to the patients that no shame or penalty attaches to asking questions; it is not a display of ignorance, but a tool to help understanding.

- It may be appropriate for practitioners to question patients about a procedure to test that patient's understanding.

\section{The Patient's Appreciation for the Personal Implications of the Decision}

A competent patient should have an understanding of the wider implications and consequences of their decision. Such implications may involve relationships with family members and friends, and any cultural and religious issues.

Practitioners should assess a patient's appreciation and understanding of the situation. Procedures may involve:

- Practitioners could ask patients if they understand the wider consequences of their decision.

- It may be relevant to discuss issues regarding relationships with family members and friends. It is likely that a practitioner may want to discuss why a patient does not want parental involvement in a decision. When appropriate, a practitioner may seek to encourage a patient to discuss the issues and treatment with family and friends.

- It may be relevant to discuss cultural and religious issues. When appropriate, a practitioner may seek to encourage patients to discuss the issues and treatment with someone from their religious or cultural groups.

- It may be appropriate for practitioners to ask patients to articulate their reasons for making their decisions. A clear explanation from the patient should demonstrate their understanding of the situation and the issues involved.

While these are some basic considerations that a health practitioner will usually take into account when assessing a child's competence, it is not an exercise in "ticking the boxes". Ultimately a practitioner must ask him or herself: "In my professional opinion, is this particular patient competent to give or refuse consent for this particular treatment?". 
A practitioner must endeavour not to allow their own personal views to cloud their judgement; the determination is of the patient's capacity to consent, not whether the patient's decision is good or bad in the practitioner's opinion.

The practitioner is responsible for the assessment and for providing reasons justifying the decision. To protect against potential liability, practitioners should make notes of their decision regarding a child's competency. Practitioners should make it clear that they considered the issue of Gillick competence. They should note whether they decided that the patient was competent or incompetent and the key reasons for reaching this decision. In cases that are more complex, notes of what information was given, what questions were asked, and what issues were discussed could be prudent. 